\title{
Erratum: Improving the contribution of foreign voluntourists in South Africa: The importance of training and supervision
}

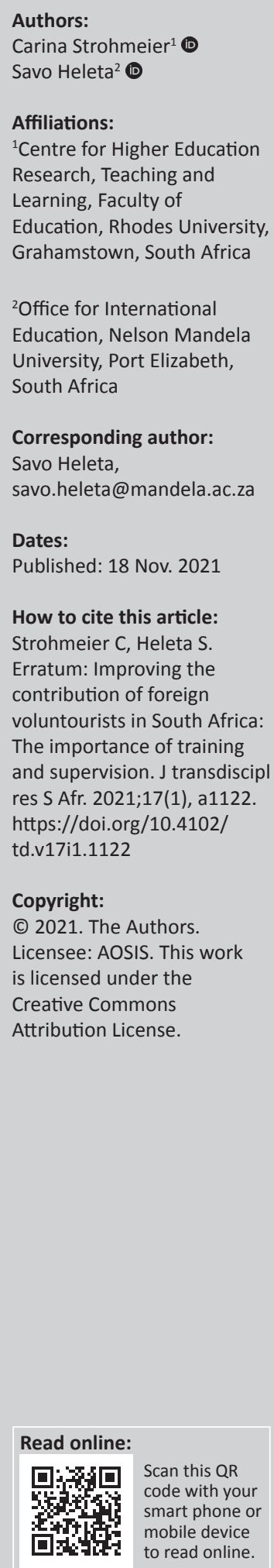

In the version of this article initially published, Strohmeier, C. \& Heleta, S., 2020, 'Improving the contribution of foreign voluntourists in South Africa: The importance of training and supervision', The Journal for Transdisciplinary Research in Southern Africa 16(1), a730. https:/ / doi. org/10.4102/td.v16i1.730, the first author's affiliation was given incorrectly in the 'Affiliation' section. The correct affiliation should be 'Centre for Higher Education Research, Teaching and Learning, Faculty of Education, Rhodes University, Grahamstown, South Africa' instead of 'Centre for Higher Education and Training, Faculty of Education, Rhodes University, Grahamstown, South Africa'.

This correction does not alter the study's findings of significance or overall interpretation of the study's results. The publisher apologises for any inconvenience caused. 